\title{
Internal Audit of Factors Affecting Mean Glandular Dose of Mammography in a North Indian Cohort
}

\author{
Veenu Singla ${ }^{1}$, Chirag K Ahuja ${ }^{2}$, Tulika Singh ${ }^{3}$, Nidhi Prabhakar ${ }^{4}$, Gurpreet Singh ${ }^{5}$, Mandeep Kang ${ }^{6}$, Niranjan Khandelwal ${ }^{7}$
}

\begin{abstract}
Aim: Increasing use of screening mammography has led to the speculation of increased incidence of radiation-induced cancer of the glandular breast tissue. The present study aimed to estimate the mammographic mean glandular dose (MGD) in North Indian females and establish the various factors which affect the radiation dose and compare it with global results.

Materials and methods: Four hundred and ninety consecutive females referred for diagnostic and screening mammography were enrolled in the study over four months duration. Standard two mammographic views of bilateral breasts, viz., mediolateral oblique (MLO) and craniocaudal (CC) views were taken generating a total of 1960 views. The tube voltage (kV), current (mA) [available as automatic exposure controls (AEC)], and other variables such as compressed breast thickness (CBT), applied compression force (CF), and MGD per projection for each breast available as digital readouts were evaluated.

Results: The mean CBT was $5.1 \pm 1.7 \mathrm{~cm}$ in CC views and $5.72 \pm 1.8 \mathrm{~cm}$ in MLO views. The mean CF was $99.8 \pm 35.9 \mathrm{~N}$ and $117.7 \pm 36 \mathrm{~N}$ in CC and MLO views respectively. The average MGD per view in CC and MLO views was $1.11 \pm 0.41 \mathrm{mGy}$ and $1.27 \pm 0.47 \mathrm{mGy}$ respectively; and the mean MGD per woman for four views was $4.76 \mathrm{mGy}$. Mean glandular dose was found to be directly proportional to the CBT, which was seen to be inversely related to age.

Conclusion: The mean MGD per view in the present study was $1.19 \mathrm{mGy}$, which is lower than average global values and is well within the stipulated guidelines of $3 \mathrm{mGy}$ set by the American College of Radiology (ACR).

Clinical significance: As there is a trend of rising incidence of breast cancer in younger women in India, this study might help to allay fears concerning radiation risk during mammography in the minds of patients, referring surgeons, gynecologists, technologists, and radiologists.

Keywords: ACR guidelines, Cohort study, Compressed breast thickness, Mammography, Mean glandular dose.

Journal of Postgraduate Medicine Education and Research (2019): 10.5005/jp-journals-10028-1325
\end{abstract}

\section{INTRODUCTION}

Breast cancer is one of the leading causes of cancer globally as well as in India., ${ }^{1,2}$ Early detection forms the cornerstone of a successful outcome of the disease. Mammography is the widely accepted screening modality for breast cancer. However, there may be theoretical increase in the incidence of radiation-induced cancer, especially with repeated examinations as in recalls or additional mammographic views, screening programs targeting younger age groups, and in higher density breasts, as breast is a radiosensitive organ (having tissue weighting factor of 0.12 ICRP 2007). ${ }^{3}$ The risk is speculated to be higher in the glandular component of the breast as it is more sensitive to radiation than the adipose tissue, as has been shown in few previous studies. ${ }^{4,5}$ For quantifying this risk, MGD is the most appropriate dosimetric quantity to predict the risk of radiation-induced carcinogenesis in the exposed breast. ${ }^{4,5}$ American College of Radiology has set 3.0 $\mathrm{mGy}$ per film as the upper limit of MGD for a $4.2 \mathrm{~cm}$ thick breast with a $50 \%$ glandular composition, with value above this being unacceptable. ${ }^{6}$

Although a lot of research on MGD determination has been carried out in various groups of population throughout the world, ${ }^{4}$ , 7-10 an elaborate and exhaustive work in the Indian subcontinent is lacking, despite this harboring one of the largest subsets of breast cancer around the globe. The present study was devised with the view to evaluate breast exposure in mammography which might aid in the formulation of appropriate reference doses as recommended by the International Atomic Energy Agency (IAEA). ${ }^{11}$

The aims of our study were as follows:
${ }^{1-4,6,7}$ Department of Radiodiagnosis, Postgraduate Institute of Medical Education and Research, Chandigarh, India

${ }^{5}$ Department of General Surgery, Postgraduate Institute of Medical Education and Research, Chandigarh, India

Corresponding Author: Veenu Singla, Department of Radiodiagnosis, Postgraduate Institute of Medical Education and Research, Chandigarh, India, Phone: +91 7087009362, e-mail: veenupgi@gmail.com

How to cite this article: Singla V, Ahuja CK, et al. Internal Audit of Factors Affecting Mean Glandular Dose of Mammography in a North Indian Cohort. J Postgrad Med Edu Res 2019;53(3):113-117.

Source of support: Nil

Conflict of interest: None

- Estimating MGD in a subgroup of females undergoing mammographic examination in North India.

- Establishing the various factors which affect the MGD like age, $\mathrm{CBT}$, and mammographic views.

- Comparing these observations and results with the other available studies in the world literature.

\section{Materials and Methods}

The study data were collected from 490 females referred for diagnostic as well as screening mammographic examination to the outpatient clinic of the Department of Radiodiagnosis at a tertiary care health center of North India over a duration spanning four months after obtaining clearance from Institute Ethics

(-) The Author(s). 2019 Open Access This article is distributed under the terms of the Creative Commons Attribution 4.0International License (https://creativecommons. org/licenses/by-nc/4.0/), which permits unrestricted use, distribution, and non-commercial reproduction in any medium, provided you give appropriate credit to the original author(s) and the source, provide a link to the Creative Commons license, and indicate if changes were made. The Creative Commons Public Domain Dedication waiver (http://creativecommons.org/publicdomain/zero/1.0/) applies to the data made available in this article, unless otherwise stated. 
Committee. All women had standard two view acquisitions of bilateral breasts, i.e., mediolateral oblique (MLO) and craniocaudal (CC) views, generating a total of 1960 views (980 each of MLO and CC projections).

All the mammograms were carried out on Siemens MAMMOMAT Novation DR system, with the available target/filter combinations of Mo/Mo, Mo/Rh, and W/Rh. The unit was appropriately calibrated for collimator assessment, tube potential reproducibility, radiation output, $A E C, C F$, chest wall missed tissue, detector uniformity, pixel map check, artifact check, and other relevant mechanical checks. During mammographic radiation exposures, AEC were chosen for tube potential $(\mathrm{kV})$ and current $(\mathrm{mA})$. The other variables, namely CBT, applied CF, and MGD per projection for each breast, were available as digital readouts.

Mean glandular dose per view was calculated using a table of factors calculated by Dance ${ }^{12}$ from the recorded exposure factors, source table data, half value layer (HVL) values, and entrance skin dose. The total glandular dose per female (for both breasts and two views) was subsequently determined. Descriptive statistics including mean were calculated for $\mathrm{CBT}, \mathrm{CF}$, and MGD per woman.

The distribution of CBT, CF, and MGD with respect to age of the patient was evaluated and the entire data generated were analyzed by the statistical analytic software (SPSS 16). Multivariate analysis of variance was used to test the significance of factors, i.e., age and CBT affecting MGD per female.

\section{Results}

The study population comprises 490 women aged 23-85 years (mean 47.5 years) with the majority being in the 5th decade (Fig. 1). The younger patients of $<40$ years were referred due to specific reasons, mostly positive family history in a first-degree relative or recent onset of a palpable lump, which was suspicious on ultrasonography. The mean kV applied was 28.40 and 28.91 in CC and MLO views respectively. The mean $\mathrm{mA}^{\prime}$ 's for CC and MLO views were 90.05 and 105.72, respectively.

The age-wise mean of CBT, CF, and MGD (Fig. 2) was determined. A histogram showing the percentage of images as a function of the MGD per view for CC and MLO views is shown in Figure 3.

Compressed breast thickness ranged from 1.55 to $12.2 \mathrm{~cm}$ in CC mammograms with a mean of $5.1 \pm 1.7 \mathrm{~cm}$ and from 1.5 to $9.6 \mathrm{~cm}$ in MLO mammograms with a mean of $5.72 \pm 1.8 \mathrm{~cm}$. Similarly, the

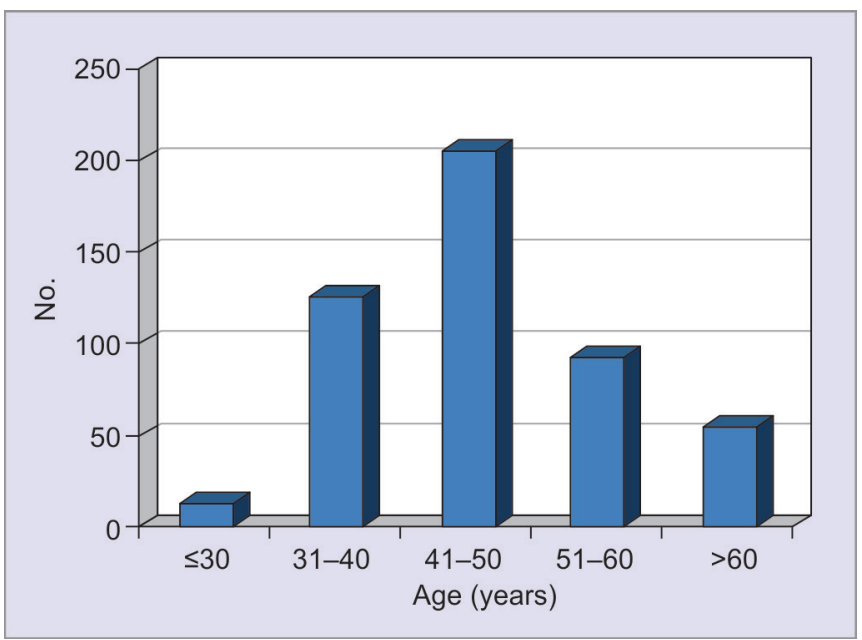

Fig. 1: Age distribution of the study population mean applied CF applied during mammographic acquisition was $99.8 \pm 35.9 \mathrm{~N}$ and $117.7+36 \mathrm{~N}$ in CC and MLO views, respectively. The average MGD in CC and MLO views was $1.11 \pm 0.41 \mathrm{mGy}$ and $1.27 \pm 0.47 \mathrm{mGy}$, respectively. The total MGD in a women was calculated by adding the MGD in all 4 views of both breasts and the mean MGD per female was $4.76 \mathrm{mGy}$. The description values for MGD, CBT, and CF for the study population are summarized in Table 1.

On multivariate analysis, it was seen that CBT and age were the two factors which had a bearing on the average MGD received by a woman. Graphs generated during regression analysis in both MLO and CC views (Fig. 4) show maximum clustering along the expected line, thereby inferring that MGD was closely dependent on CBT. The correlation coefficients (Pearson's) obtained in the MLO and CC views were 0.167 and 0.315 . The total dose received by a female was seen to progressively decrease with age as shown in Figure 5.

\section{Discussion}

As glandular tissue of the breast is one of the most vulnerable tissues for the development of radiation-induced cancers, assessment and quantification of radiation dose has become necessary, especially in the light of increased frequency of screening mammographies being performed in younger age group as breast cancer is showing a tendency to affect younger females in India. Mean glandular dose has been found to be the most appropriate dosimetric quantity to predict this radiation risk. Although standard guidelines have been adopted by various international agencies in the radiation control programs, no such guidelines exist in context to the Indian subcontinent.

The various tabulations in our study indicate that the CBT was higher in the MLO projection $(5.72 \mathrm{~cm})$ than in the CC view $(5.1 \mathrm{~cm})$ by $12 \%$. This indicates that the breast is thinner on the CC than the MLO view. This is probably related to the inclusion of the pectoralis major muscle in the MLO view which adds to the breast tissue thickness, thus enhancing the apparent CBT of the breast. These observations are in congruence with those reported by previous authors..$^{10,13-15}$ Similar trends were also seen in the mean MGD per view which was marginally higher for MLO view (1.27 mGy) than CC view (1.11 $\mathrm{mGy}$ ) by $14.4 \%$.

Figure 2 shows that CBT decreases progressively with age. This is probably due to a progressive reduction in the breast thickness with increasing age due to increase in the laxity of the skin and subcutaneous tissue and reduction in the glandular component. Similar trend is seen in MGD values per female (Fig. 5). This closely paralleled association between MGD, CBT, and age indicates that age has a bearing on the MGD through a variety of factors such as the decrease in CBT and progressive reduction in the breast glandularity. Reduced CBT decreases the length of the path traversed by the X-rays and hence results in less deposition of energy across the travelled path, thereby accounting for the reduced MGD.

\section{Comparison with Other Studies}

A comparative tabulation of MGD and CBT in various studies across the globe is given in Table 2. The difference in the CBT values seen in different groups of population across the globe is probably due to a combination of various factors such as the difference in the method of generation of CF, difference in CBT measurement techniques, and most importantly due to the difference in the ethnicity and 

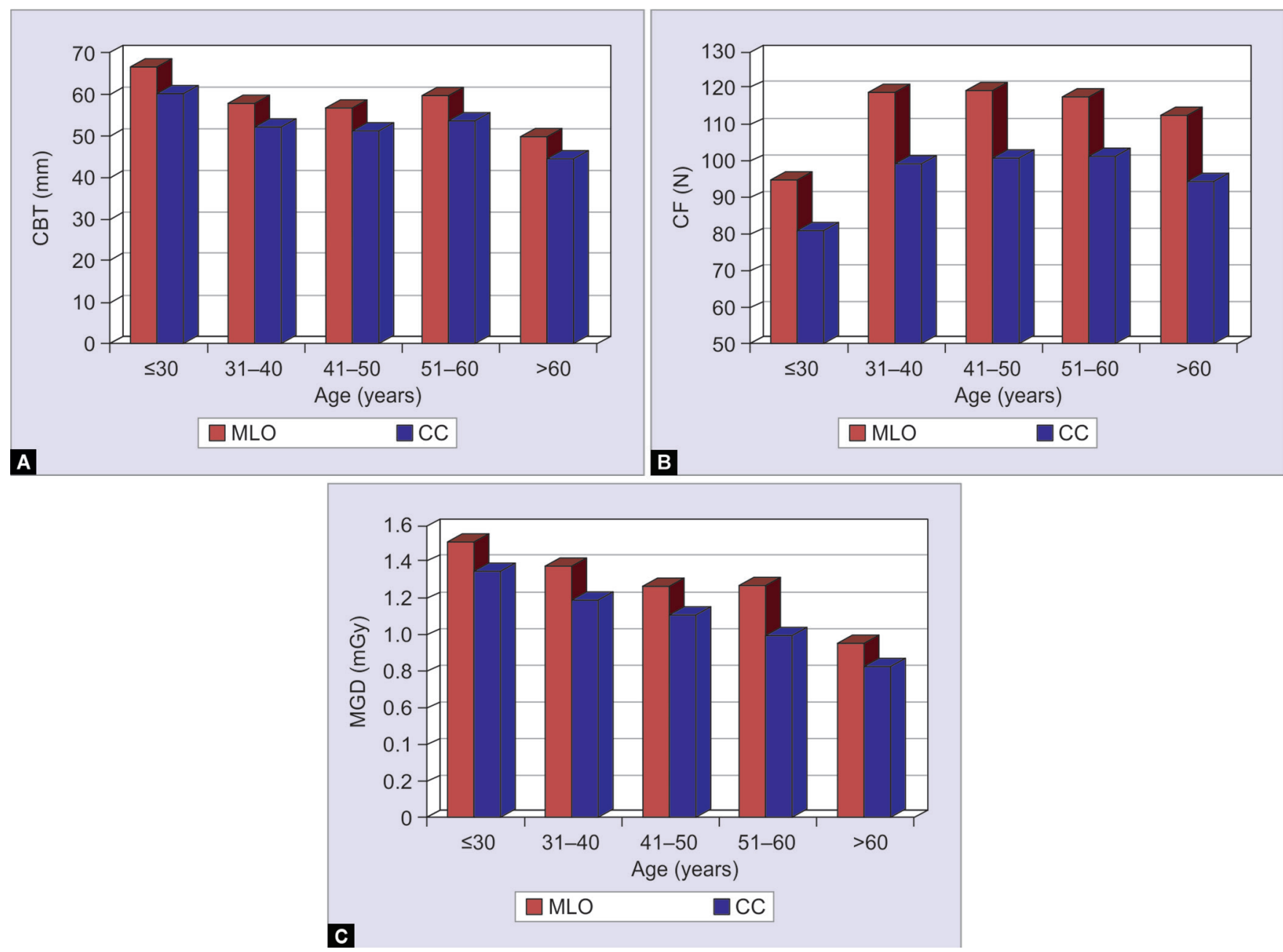

Figs 2A to C: Histograms showing (A) Compressed breast thickness (CBT); (B) Applied compression force (CF); (C) Mean glandular dose (MGD) as a function of age for mediolateral oblique (MLO) and craniocaudal (CC) projections

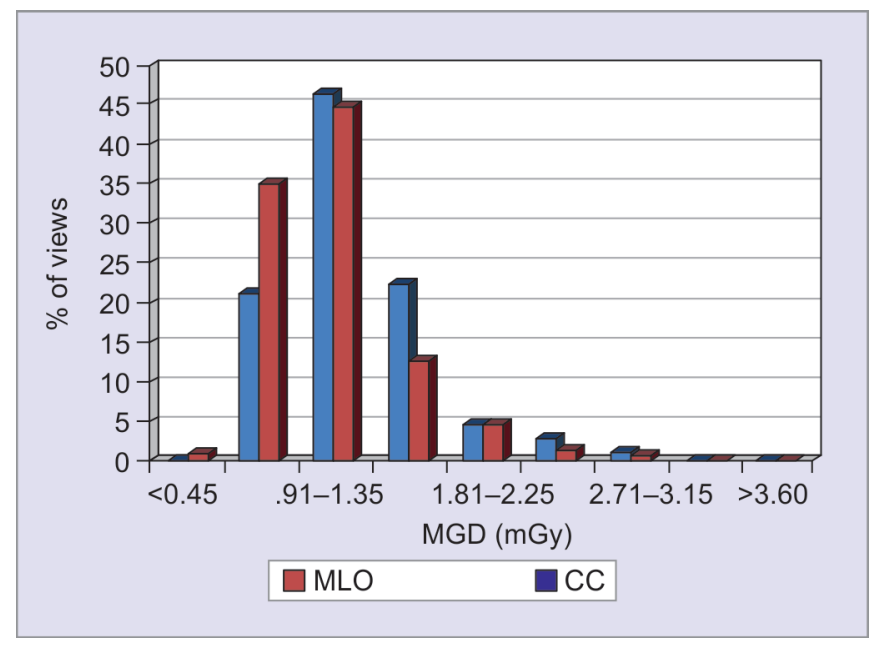

Fig. 3: Histogram showing the percentage of images as a function of the mean glandular dose (MGD) per view for mediolateral oblique (MLO) and craniocaudal (CC) projections

body habitus of the radiographed females. The mean MGD per view was relatively less in Indian females as compared to the rest of the world, probably on account of more of fatty composition and less breast glandularity in this population. The results were
Table 1: Details of evaluated parameters - compressed breast thickness, mean glandular dose, and compression force

\begin{tabular}{lccr}
\hline & \multicolumn{3}{c}{ Mean values } \\
\cline { 2 - 4 } Views & $C B T(\mathrm{~mm})$ & $M G D(m G y)$ & $C F(\mathrm{~N})$ \\
\hline RMLO & $57.18 \pm 18.409$ & $1.258 \pm 0.4852$ & $117.53 \pm 39.061$ \\
RCC & $50.91 \pm 18.602$ & $1.102 \pm 0.4401$ & $101.41 \pm 41.256$ \\
LMLO & $57.33 \pm 19.926$ & $1.290 \pm 0.6032$ & $117.84 \pm 43.001$ \\
LCC & $52.39 \pm 19.044$ & $1.165 \pm 0.5133$ & $98.21 \pm 39.135$ \\
\hline
\end{tabular}

CBT, compressed breast thickness; MGD, mean glandular dose; CF, compression force; RMLO, right mediolateral oblique; RCC, right craniocaudal; LMLO, left mediolateral oblique; LCC, left craniocaudal

comparable with the UK studies, ${ }^{13,15}$ indicating closer resemblance of the Indian population with the British counterparts. The MGD in diagnostic mammography of 420 exposures in a population in China was $1.6 \mathrm{mGy}$, which was also lower than the guidance levels in International Basic Safety Standards (IBSS). ${ }^{19}$ However, a study of MGD in six mammography units in Santiago, Chile, found the dose to range between 0.64 and $7.26 \mathrm{mGy}$ for a breast thickness range of $20-70 \mathrm{~mm}$, respectively, therefore highlighting the necessity to optimize doses. ${ }^{20}$

The major limitation of this study was the small sample size and also that breast density was not assessed simultaneously in every 


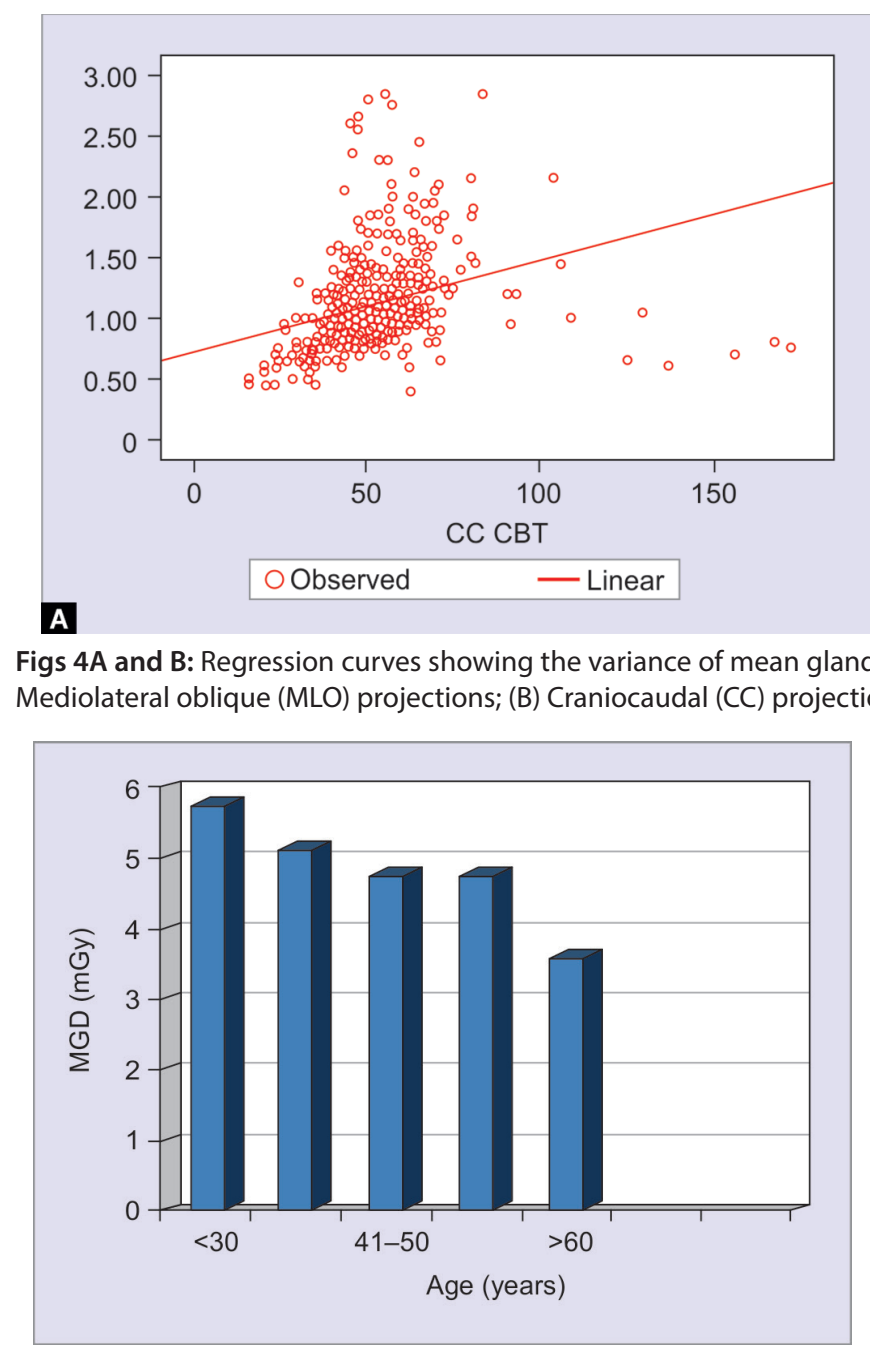

Fig. 5: Histogram showing mean glandular dose (MGD) per woman as per age Mediolateral oblique (MLO) projections; (B) Craniocaudal (CC) projections

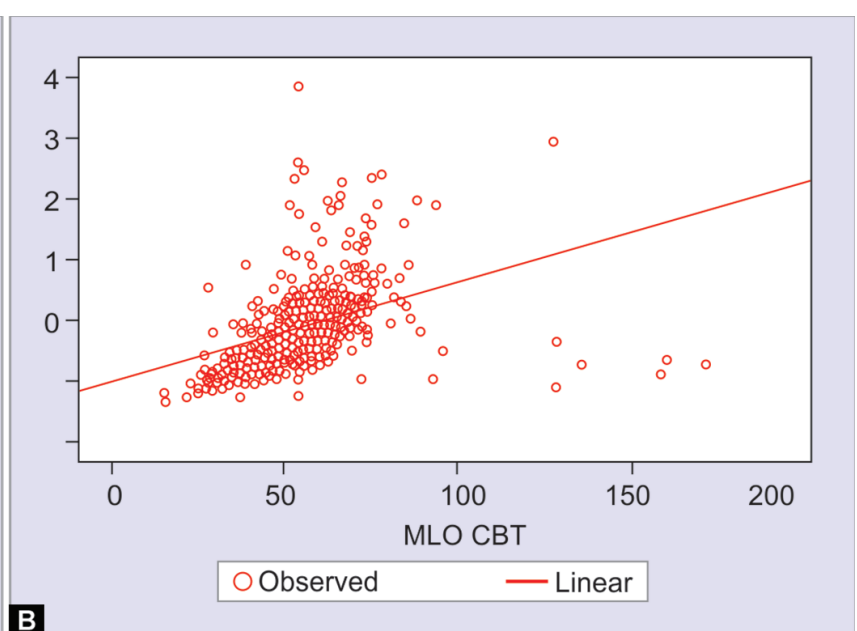

B

Figs 4A and B: Regression curves showing the variance of mean glandular dose (MGD) per view with compressed breast thickness (CBT) for (A)

Table 2: Comparison of mean glandular dose in mammography with other global studies

\begin{tabular}{|c|c|c|c|c|c|c|c|c|}
\hline \multirow[b]{2}{*}{ Data source } & \multirow[b]{2}{*}{ Country } & \multirow[b]{2}{*}{ Protocol } & \multirow[b]{2}{*}{$\begin{array}{l}\text { Conversion } \\
\text { factor }\end{array}$} & \multirow[b]{2}{*}{ No. of women } & \multirow[b]{2}{*}{$\begin{array}{l}\text { Mean age } \\
\text { (years) }\end{array}$} & \multirow[b]{2}{*}{ Mean CBT $(\mathrm{mm})$} & \multicolumn{2}{|c|}{$M G D$} \\
\hline & & & & & & & $\begin{array}{l}\text { Per film } \\
\text { (mGy) }\end{array}$ & $\begin{array}{l}\text { Perwoman } \\
(m G y)\end{array}$ \\
\hline \multirow[t]{2}{*}{ Heggie et al. $^{7}$} & Australia & Victorian & Wu et al. ${ }^{16}$ & 490 & & $(C C+M L O): 52$ & Median: 2.17 & Median: 4.42 \\
\hline & & states & & & & & Mean: 2.26 & Mean: 4.6 \\
\hline \multirow[t]{3}{*}{ Eklund et al. ${ }^{14}$} & Sweden & & Rosenstein & 1,350 & 54 & 50 & Mean: 1.25 & \\
\hline & & & et al. ${ }^{17}$ & 1,596 & & 54 & & Mean: 0.68 \\
\hline & & & & 1,496 & & 62 & & Mean: 0.76 \\
\hline \multirow[t]{2}{*}{ Klein et al. ${ }^{4}$} & Germany & & Klein et al. ${ }^{4}$ & 1,678 & 53.6 (group I) & 55.9 & Mean: 1.59 & \\
\hline & & & & 945 & & 50.8 & Mean: 2.07 & \\
\hline Gentry and DeWerd ${ }^{9}$ & USA & & Wu et al. ${ }^{16}$ & 4,400 & & CC: 45 & Mean: 1.49 & \\
\hline \multirow[t]{2}{*}{ Burch and Goodman ${ }^{15}$} & UK & IPSM & Dance $^{18}$ & 4,633 & Not recorded & CC: 52 & Median: 1.4 & Median: 3.3 \\
\hline & & & & & & MLO: 54 & Median: 1.7 & \\
\hline \multirow[t]{2}{*}{ Jamal et al. ${ }^{10}$} & Malaysia & ACR & Wu et al. ${ }^{16}$ & 300 & 51 & CC: 37.5 & Median: 1.44 & Mean: 3.37 \\
\hline & & & Dance et al. ${ }^{12}$ & & & MLO: 44.5 & Median: 1.65 & Median: 3.21 \\
\hline \multirow[t]{2}{*}{ Du et al. ${ }^{19}$} & China & European & Dance et al. ${ }^{12}$ & 420 & 45 & CC: 43 & Median: 1.45 & \\
\hline & & & & & & MLO: 38.9 & Median: 1.47 & \\
\hline \multirow[t]{2}{*}{ Present study } & India & ACR & Dance et al. ${ }^{12}$ & 490 & 47.5 & CC: 51 & Mean: 1.11 & Mean: 4.76 \\
\hline & & & & & & MLO: 57.2 & Mean: 1.27 & \\
\hline
\end{tabular}

CBT, compressed breast thickness; MGD, mean glandular dose; CC, craniocaudal; MLO, mediolateral oblique; IPSM, Institute of Physical Sciences in Medicine; ACR, American College of Radiology patient. However, few recent studies have shown no association of breast radiation dose with density. ${ }^{21}$ Moreover, it is a single institution and single manufacturer study. However, the study may provide a preliminary impetus to the health professionals and regulatory authorities to plan a multicentric study as mammography is being increasingly used in our country without any established MGD guidelines.

\section{Conclusion}

The mean MGD per view in the present study is $1.19 \mathrm{mGy}$, which is well within the stipulated guidelines of $3 \mathrm{mGy}$ set by the ACR. As there is a trend of rising incidence of breast cancer in younger women in India, this study might help to allay fears in the minds of patients, referring surgeons, gynecologists, technologists, and radiologists concerning mammography. This is especially so in women requiring regular annual or biannual follow-up and women requiring additional mammographic views. 


\section{Clinical Significance}

As there is a trend of rising incidence of breast cancer in younger women in India, this study might help to allay fears in the minds of patients, referring surgeons, gynecologists, technologists, and radiologists concerning radiation risk during mammography. This is especially so in women requiring regular annual or biannual follow-up and women requiring additional mammographic views.

\section{REFERENCES}

1. Murthy NS, Agarwal UK, et al. A study on time trends in incidence of breast cancer-Indian scenario. Eur J Cancer Care (Engl) 2007;16: 185-186. DOI: 10.1111/j.1365-2354.2006.00761.x.

2. Agarwal G, Ramakant P. Breast Cancer Care in India: The Current Scenario and the Challenges for the Future. Breast Care (Basel) 2008;3:21-27.

3. The 2007 Recommendations of the International Commission on Radiological Protection PUB, 103, Ann. ICRP. 2007;37:1-332.

4. Klein $\mathrm{R}$, Aichinger $\mathrm{H}$, et al. Determination of average glandular dose with modern mammography units for two large groups of patients. Phys Med Biol 1997;42:651-671. DOI: 10.1088/0031-9155/42/ $4 / 004$.

5. Beckett JR, Kotre CJ. Dosimetric implications of age related glandular changes in screening mammography. Phys Med Biol 2000;45: 801-813. DOI: 10.1088/0031-9155/45/3/316.

6. American College of Radiology Committee on Quality Assurance in Mammography. Mammography quality control manual, medical physicist's section. Reston, VA: ACR; 1999.

7. Heggie JC. Survey of doses in screening mammography. Australas Phys Eng Sci Med 1996 Dec;19(4):207-216.

8. Sookpeng S, Ketted P. Mean Glandular dose from routine mammography. Naresuan Univ J 2006;14:19-26.

9. Gentry JR, DeWerd LA. TLD measurements of in vivo mammographic exposures and the calculated mean glandular dose across the United States. Med Phys 1996 Jun;23(6):899-903. DOI:10.1118/ 1.597824 .
10. Jamal $\mathrm{N}, \mathrm{Ng} \mathrm{KH}$, et al. A study of mean glandular dose during diagnostic mammography in Malaysia and some of the factors affecting it. Br J Radiol 2003;76:238-245. DOI: 10.1259/bjr/ 66428508 .

11. International Atomic Energy Agency. International basic safety standards for protection against ionising radiation and for the safety of radiation sources, Safety Series no. 115-1. Vienna, Austria: IAEA; 1996.

12. Dance DR, Skinner CL, et al. Additional factors for the estimation of mean glandular breast dose using the UK mammography dosimetry protocol. Phys Med Biol 2000;45:3225-3240. DOI: 10.1088/00319155/45/11/308.

13. Young KC. Radiation doses in the UK trial of breast screening in women aged 40-48 years. Br J Radiol 2002;75:362-370. DOI: 10.1259/ bjr.75.892.750362.

14. Eklund S, Thilander A, et al. The impact of anatomic variations on absorbed radiation doses in mammography. Radiat Prot Dosimetry 1993;49:167-170. DOI: 10.1093/rpd/49.1-3.167.

15. Burch A, Goodman DA. A pilot survey of radiation doses received in the United Kingdom Breast Screening Programme. Br J Radiol 1998;71:517-527. DOI: 10.1259/bjr.71.845.9691897.

16. Wu X, Barnes GT, et al. Spectral dependence of glandular tissue dose in screen-film mammography. Radiology 1991;179:143-148. DOI: 10.1148/radiology.179.1.2006265.

17. Rosenstein M, Andersen LW, et al. US Department of Health and Human Services. Handbook of glandular tissue doses in mammography, p. 16. FDA Report 1985;85-8239.

18. Dance DR. Monte Carlo calculation of conversion factors for the estimation of mean glandular breast dose. Phys Med Biol 1990;35:1211-1219. DOI: 10.1088/0031-9155/35/9/002.

19. Du X, Wang J, et al. Investigation of mean glandular dose in diagnostic mammography in China. Biomed Environ Sci 2014;27:396-399.

20. Leyton F, Nogueira Mdo S, et al. Mean glandular dose in six digital mammography services in Santiago, Chile: preliminary reference levels. Radiat Prot Dosimetry 2015;165:115-120.

21. Nguyen JV, Williams MB, et al. Do women with dense breasts have higher radiation dose during screening mammography? Breast $J$ 2018;24:35-40. DOI: 10.1111/tbj.12833. 